\title{
Association between the ankle-brachial index, intermittent claudication, and physical activity level: what is the influence on the functional capacity of patients with or at high risk of cardiovascular disease?
}

This article was published in the following Dove Press journal:

International Journal of General Medicine

23 January 2015

Number of times this article has been viewed

\author{
Tiago José Nardi Gomes' \\ Isabella Martins de \\ Albuquerque ${ }^{2}$ \\ Patrícia de Moraes Costa ${ }^{3}$ \\ Dannuey Machado \\ Cardoso ${ }^{4}$ \\ Gabriela de Moraes Costa ${ }^{5}$ \\ José Luiz da Costa Vieira ${ }^{6}$ \\ 'Department of Physiotherapy, \\ UNIFRA, Centro Universitário \\ Franciscano, Santa Maria, RS, Brazil; \\ ${ }^{2}$ Department of Physiotherapy and \\ Rehabilitation, Universidade Federal \\ de Santa Maria, Santa Maria, RS, Brazil; \\ ${ }^{3}$ Department of Clinical Medicine, \\ Universidade Federal de Santa Maria, \\ Santa Maria, RS, Brazil; ' ${ }^{4}$ epartment \\ of Physiotherapy, Universidade \\ de Santa Cruz do Sul, Santa Cruz \\ do Sul, RS, Brazil; ${ }^{5}$ Department \\ of Neuropsychiatry, Universidade \\ Federal de Santa Maria, Santa Maria, \\ RS, Brazil; ${ }^{6}$ Fundação Universitária de \\ Cardiologia, Instituto de Cardiologia, \\ Porto Alegre, RS, Brazil
}

Correspondence: Tiago José Nardi Gomes, Department of Physiotherapy, Centro Universitário Franciscano, Rua Silva Jardim, I I75, CEP 970 I0-49 I Santa Maria-RS, Brazil.

Tel +55 553025 I 202

Fax +55 5530259002

Email tiagonardi@yahoo.com.br
Background: Patients with or at high risk of cardiovascular disease have a poor functional capacity; however, the influence of association among intermittent claudication (IC), abnormal ankle-brachial index (ABI), and physical activity level on functional capacity of these patients has not been fully studied.

Objective: The primary objective of this study was to investigate the association between the ABI, IC, and physical activity level, and the influence of these variables on the functional capacity of patients with or at high risk of cardiovascular disease seen in a reference cardiology outpatient clinic in Southern Brazil. The secondary objective was to assess the prevalence of peripheral arterial disease (PAD) in this sample of patients.

Patients and methods: This was a prospective cross-sectional study in which 162 consecutive patients were evaluated and classified into three groups according to their ABI: normal ABI ( $n=104$, values between 1.00 and 1.40); borderline PAD ( $n=23$, values between 0.91 and 1.00); and patients with PAD $(n=35, \leq 0.90)$. The presence of IC was assessed using the Edinburgh Claudication Questionnaire. The level of physical activity was assessed by the short version of the International Physical Activity Questionnaire (IPAQ) and functional capacity was assessed by the 6-minute walk distance (6MWD).

Results: The prevalence of PAD was $21.6 \%$ in the total sample. The 6MWD showed strong correlation with the absence of IC $(r=0.785 ; P<0.001)$, moderate correlation with age $(r=-0.347$; $P<0.001)$, and weak correlations with IPAQ scores $(r=0.164 ; P=0.038)$ and ABI $(r=0.216$; $P=0.006)$. Age, $\mathrm{ABI}$, and absence of IC were independently associated with the outcome ( $P=0.001, P=0.001$, and $P=0.028$, respectively).

Conclusion: The current study demonstrates that 6MWD is associated with IPAQ scores, ABI, and absence of IC. Age, ABI and absence of IC were independently associated with functional capacity in patients with or at high risk of cardiovascular disease.

Keywords: 6-minute walk test, cardiology outpatient clinic, IPAQ, peripheral arterial disease

\section{Introduction}

The projection of the Global Burden of Diseases study for 2020 indicates that cardiovascular diseases (CVD) remain the leading cause of death and disability, particularly in developing countries. ${ }^{1}$ The risk of developing CVD depends to a large extent on the presence of several risk factors. ${ }^{2}$ It is well know that major risk factors for CVD 
include cigarette smoking, older age, diabetes, hypertension, hypercholesterolemia, obesity, and physical inactivity. ${ }^{2}$

The ankle-brachial index (ABI), which is the ratio of the ankle and brachial systolic blood pressures, is quick and easy to measure and has been used for many years in vascular practice to confirm the diagnosis and assess the severity of peripheral artery disease (PAD) in the legs. ${ }^{3}$ However, the ABI is also an indicator of generalized atherosclerosis because lower levels have been associated with higher rates of concomitant coronary and cerebrovascular disease, and with the presence of cardiovascular risk factors. ${ }^{3}$ A Brazilian multicenter study has reported that PAD is associated with the presence of diabetes, a sedentary lifestyle, total and abdominal obesity, stroke, and ischemic heart disease. ${ }^{4}$ Significantly, PAD impairs functional capacity and quality of life. ${ }^{5}$ Its classic symptom is intermittent claudication (IC) - that is leg pain with walking that improves with rest. However, most patients do not have IC, and rather have atypical leg symptoms or no symptoms at all. ${ }^{6,7}$

Therefore, assessment of functional capacity in patients with or at high risk of CVD is an important tool that reflects integrated efforts with regards to the health of the pulmonary and cardiovascular systems, peripheral and systemic circulation, neuromuscular units, and muscle metabolism. ${ }^{8}$ In this context, the 6-minute walk test (6MWT), which was first used in patients undergoing cardiac rehabilitation, is a simple, easy-to-perform, low-tech, safe, and well-established self-paced assessment tool to quantify functional capacity in outpatients. ${ }^{9}$ The test is reflective of the activities of daily living and evaluates the global and integrated responses of all the systems involved during exercise. ${ }^{10}$ The $6 \mathrm{MWT}$ is performed by instructing the participant to walk as fast as possible (without running) on a horizontal surface for 6 minutes, and the distance walked (6MWD) is recorded. ${ }^{10}$

Several tools are currently used to detect disease progression both at diagnosis and during the follow-up of CVD patients. Considering that the relevance of $\mathrm{ABI}$ and functional capacity assessments provide important prognostic information on the course of these patients, which may aid clinical management by prompting initiation or intensification of treatment, and hemodynamically significant atherosclerosis is the initiating factor in the impaired functional capacity characteristic of $\mathrm{PAD},{ }^{11}$ the purpose of this study was to investigate the association between ABI, IC, and physical activity level, and the influence of these variables on functional capacity in a sample of stable patients, either with or at a high risk of CVD. The secondary objective was to assess the prevalence of PAD in this sample of patients from a reference cardiology outpatient clinic in Southern Brazil.

\section{Material and methods Study design}

This was a prospective cross-sectional study in which 162 consecutive patients who had either a high cardiovascular risk or CVD (89 male, average $65.1 \pm 7.7$ years) seen in a reference cardiology outpatient clinic were assessed using the ABI, the International Physical Activity Questionnaire (IPAQ), the 6MWD, and the Edinburgh Claudication Questionnaire. The patients were classified into three groups according to their ABI: normal ( $n=104$, values between 1.00 and 1.40); borderline PAD ( $n=23$, values between 0.91 and 1.00); and patients with $\operatorname{PAD}(\mathrm{n}=35, \leq 0.90)$.

\section{Study population}

We included consecutive patients of both sexes, aged 55 years and older, who met at least one of the criteria for high cardiovascular risk classification: coronary artery disease, cerebrovascular disease, diabetes mellitus, and metabolic syndrome. Study participants were recruited at the outpatient clinic of the Cardiology Institute/University Foundation of Cardiology (IC-FUC), Porto Alegre, Brazil, during July and August 2010. We also included patients with at least three risk factors for atherosclerosis - hypertension, smoking, dyslipidemia, age $>70$ years, family history of coronary artery disease, chronic kidney disease, or asymptomatic carotid artery disease - and stable patients who had documented chronic CVD and were receiving regular long-term care at the outpatient clinic. All included patients were outpatients and clinical stability was evidenced by no recent hospitalization.

Patients with chronic heart failure, unstable angina, uncontrolled systemic arterial hypertension, respiratory disease, inability to perform a 6MWT, and muscular, neurological, or psychiatric disorders were excluded from the study.

This study was approved by the Research Ethics Committee of IC-FUC and informed consent was obtained from all patients.

\section{Clinical definitions}

Stable coronary artery disease was defined as clinical presentation of stable angina (according to the Canadian Cardiovascular Society) or silent ischemia. ${ }^{12}$ Cerebrovascular disease was defined by stroke, transient ischemic attack, and subarachnoid hemorrhage. ${ }^{13}$ Diabetes was defined by a fasting plasma glucose level of $126 \mathrm{mg} / \mathrm{dL}$ or higher or, for patients 
with fasting glucose level of $200 \mathrm{mg} / \mathrm{dL}$ or higher, a positive oral glucose tolerance test. ${ }^{14}$ Metabolic syndrome was defined according to the diagnostic criteria adopted by the US National Cholesterol Education Program's Adult Treatment Panel III (NCEP-ATP III) and included the association of three or more of the following components: waist circumference for men $>102 \mathrm{~cm}$ and for women $>88 \mathrm{~cm}$; triglycerides $\geq 150 \mathrm{mg} / \mathrm{dL}$; high-density lipoprotein cholesterol for men $<40 \mathrm{mg} / \mathrm{dL}$ and for women $<50 \mathrm{mg} / \mathrm{dL}$; systolic blood pressure $\geq 130 \mathrm{mmHg}$ or diastolic pressure $\geq 85 \mathrm{mmHg}$; and fasting glucose $\geq 110 \mathrm{mg} / \mathrm{dL} .{ }^{15}$ Cigarette smoking classification was based on history and current smokers were defined as those having smoked at least 100 cigarettes over their lifetime and currently smoking daily or occasionally. ${ }^{16}$ The diagnosis of hypertension was defined by the Fourth Brazilian Hypertension Consensus. ${ }^{17}$ Dyslipidemia was defined by one or more abnormal blood levels (total cholesterol $>200 \mathrm{mg} / \mathrm{dL}$; high-density lipoprotein-cholesterol $<50 \mathrm{mg} / \mathrm{dL}$ for women and $<40 \mathrm{mg} / \mathrm{dL}$ for men; low-density lipoprotein cholesterol $>160 \mathrm{mg} / \mathrm{dL}$; and triglycerides $>150 \mathrm{mg} / \mathrm{dL}$ ) or current use of a lipid-lowering treatment. ${ }^{18}$ Asymptomatic coronary artery disease was assessed by duplex scanning and defined on the basis of the blood flow velocity patterns at baseline in both carotid arteries. ${ }^{19}$

\section{Procedures}

Demographic data and medical history were collected using a standard questionnaire and recording form. Data were derived from both the subject and their medical records.

\section{$\mathrm{ABI}$ measurement}

To measure the $\mathrm{ABI}$, the patient remained in the supine position for a 5-minute period before measurements. A specific cuff for upper limbs was used to assess systolic pressures of both limbs. ${ }^{20}$ The cuff was inflated at $20 \mathrm{mmHg}$ above systolic arterial pressure. Pressure was recorded using a portable Doppler device (model DV-2001; MEDPEJ, São Paulo, Brazil) placed on the brachial arterial in the cubital fossa. A specific cuff for lower limbs was placed above the malleolus to measure systolic pressures of each limb. A Doppler probe was placed on the posterior tibial and dorsal foot arteries. ${ }^{20}$ Two experienced technicians performed this evaluation using the same device. The ABI was the highest systolic pressure value of the lower limbs divided by the higher of the brachial artery pressures. ${ }^{21}$ Subjects who had an ABI value $\leq 0.90$ in either leg were categorized as having PAD. Subjects with ABI 0.91-1.00 were considered as borderline PAD. ABI $>1.00-1.40$ was considered normal, as defined in the $2011 \mathrm{ACCF} / \mathrm{AHA}$ focused update of the guidelines for the management of patients with PAD of the American College of Cardiology Foundation/American Heart Association Task Force on Practice Guidelines. ${ }^{22}$

\section{Evaluation of the physical activity level}

The IPAQ short version, already translated into Portuguese and validated for the Brazilian population, ${ }^{23}$ was used to determine the level of physical activity. The questionnaire was individually applied by the main investigator, and consisted of questions about the frequency (days per week) and time (minutes per day) spent on walks and performing activities involving moderate and intense physical effort in four domains (work, commuting to work, household duties, leisure). ${ }^{24}$ For the study, the levels of physical activity were classified as sedentary, insufficiently active, sufficiently active, and very active as previously described by Matsudo et al. ${ }^{25}$ For the purpose of analysis, this classification was converted to a continuous score to allow for an estimation of energy expenditure expressed as metabolic equivalent (MET) per minute per week. To perform this calculation, one multiplies the value of the energy expenditure in MET of the evaluated activity by the frequency in days per week and the time in minutes reported for each activity.

\section{Evaluation of functional capacity}

Functional capacity was evaluated through the 6MWD. A single walk test without practice was performed in a plane corridor 30 meters in length, following the recommendations of the American Thoracic Society. ${ }^{10}$ Patients were instructed to walk for 6 minutes, according to their tolerance. The result of the 6MWT is expressed as distance walked (meters) and is compared with the predicted values. ${ }^{26}$ The Borg scale was used to rate perceived exertion and the perceived level of dyspnea was rated on the Borg category ratio scale. ${ }^{27}$ At the end of the $6 \mathrm{MWT}$, the main investigator measured the total distance walked by the patient.

\section{IC assessment}

The presence of IC was defined by the criteria of the Edinburgh Claudication Questionnaire, validated for Brazilian Portuguese. ${ }^{28}$

\section{Sample size calculation}

To estimate the sample size, a pilot study was conducted using a protocol identical to that described above in a group of 30 patients. Based on these preliminary results, the standard deviation of the change in 6MWD for patients with abnormal ABI values compared to normal ABI (predicting 
an abnormal ABI from 25\%) was 50 meters. A sampling error of $2 \%$, a two-sided alpha of $5 \%$, and a statistical power of $80 \%$ were required, thus resulting in the inclusion of at least 148 patients.

\section{Statistical analysis}

Normally distributed continuous data are expressed as mean values ( \pm standard deviation). Non-normally distributed continuous data are expressed as median (interquartile range). Frequencies of categorical variables are expressed as numbers (percentage). The Kolmogorov-Smirnov test was used to verify the data distribution. Participants were stratified according to the presence of PAD or according to the ABI values $(\leq 0.90$; $0.91-1.00 ;>1.00-1.40)^{29}$ and were compared using analysis of variance with Tukey's post hoc tests, or Kruskal-Wallis $H$-tests and Pearson's chi-squared tests according to their type and distribution of the group involved in the comparisons. Pearson's correlation coefficient was used to examine the relationships between the selected variables and the outcome. Since the IPAQ score was non-normally distributed, this parameter was log transformed. A multiple linear regression model was used to determine the ability of the independent variables (age, IPAQ score, ABI, and absence of IC) to explain the variance in 6MWD. The significance of the final model was tested by the analysis of variance $F$-test, and the goodness of fit was assessed by the adjusted coefficient of determination (adjusted $R^{2}$ ). All statistical analyses were performed using the software Statistical Package for the Social Sciences (SPSS 20.0; IBM Corporation, Armonk, NY, USA). The significance level was set at $5 \%(P<0.05)$.

\section{Results}

Table 1 shows the baseline characteristics, eligibility criteria, medication use, presence of IC, ABI, 6MWD, and score of physical activity of the study population according to the ABI values in the total sample and by group. All participants completed the 6MWT without interruption. Less than $20 \%$ of 32 symptomatic PAD patients reported claudication during the test. The baseline characteristics, eligibility criteria, and medication use data were similar among the three study groups, except that the average age was higher in the PAD group as compared to the normal group $(P=0.002)$, the age $>70$ years was higher in the borderline and PAD groups as compared to the normal group ( $P=0.003)$, and the proportion of users of angiotensin-converting enzyme inhibitors was higher in the normal group as compared to the borderline group $(P=0.045)$. The assessment of physical activity showed that all patients were classified as sufficiently active.
The prevalence of PAD was $21.6 \%$ in the total sample and the most prevalent cardiovascular risk factors were hypertension $(93.2 \%)$, coronary artery disease $(80.2 \%)$, and metabolic syndrome (71.1\%). The 6MWD was significantly lower in patients with borderline PAD compared with in patients with normal ABI $(P=0.009)$. Significant differences between the groups $(P=0.046)$ were also found in the 6MWD when it was evaluated as the percent of predicted distance. Most (91.4\%) of the 35 patients with PAD had IC, compared with $4.3 \%$, and $8.7 \%$ of participants with borderline PAD and normal ABI, respectively $(P<0.001)$. In the total sample of patients, the 6MWD showed strong positive correlation with the absence of IC $(r=0.785: P<0.001)$ and moderate negative correlation with age $(r=-0.347 ; P<0.001)$. However, 6MWD showed weak positive correlations with IPAQ score $(r=0.164$; $P=0.038)$ and ABI $(r=0.216 ; P=0.006)$ (Table 2$)$.

Furthermore, estimation of 6MWD using multiple linear regression including age, $\mathrm{ABI}$, and the absence of IC explained $14 \%$ of the variability in 6 MWD $\left(R_{\text {adjusted }}^{2}=0.147\right)$ (Table 3).

\section{Discussion}

The purpose of the study was to investigate the association between ABI, IC, and physical activity level, and the influence of these variables on functional capacity in a sample of stable patients either with or at a high risk of CVD recruited from a reference cardiology outpatient clinic in Southern Brazil. The main findings of the study were as follows: 1) functional capacity, assessed by the 6MWD, showed strong positive correlation with the absence of IC and moderate negative correlation with age; 2 ) in addition, weak positive correlations were observed between functional capacity, IPAQ score, and $\mathrm{ABI}$; and 3) functional capacity was independently associated with age, ABI, and IC. To our knowledge, this is the first study to demonstrate, in stable patients either with or at a high risk of CVD seen in a reference cardiology outpatient clinic, a relationship between greater functional capacity and high ABI values, an active level of physical activity, absence of IC, and lower age, as well as being the first study to confirm that age, ABI, and absence of IC can be used for the prediction of functional capacity.

Our study shows that PAD was highly prevalent (21.6\%) in stable patients either with or at a high risk of CVD. Comparison of our study with existing studies estimating the prevalence of PAD is difficult given the different study populations. For example, a recent study conducted in Brazil identified a PAD prevalence of $21.1 \%$ in Japanese Brazilians by measurement of the ABI. The study population 
Table I Characteristics of the study sample

\begin{tabular}{|c|c|c|c|c|c|}
\hline Baseline characteristics & $\begin{array}{l}\text { Normal ABI } \\
(n=104)\end{array}$ & $\begin{array}{l}\text { Borderline PAD } \\
(n=23)\end{array}$ & $\begin{array}{l}\text { PAD } \\
(n=35)\end{array}$ & $\begin{array}{l}\text { Total } \\
(n=162)\end{array}$ & $P$-value* \\
\hline Male sex, n (\%) & $65(62.5)$ & $14(60.9)$ & $25(7 \mathrm{I} .4)$ & $104(64.2)$ & 0.595 \\
\hline Age (years), mean $\pm S D$ & $63.4 \pm 6.6$ & $66.4 \pm 8.8$ & $68.4 \pm 7.6$ & $64.9 \pm 7.4$ & $0.002^{\mathrm{a}}$ \\
\hline Caucasian ethnicity, n (\%) & $93(89.4)$ & $20(87.0)$ & $33(94.3)$ & $146(90.1)$ & 0.153 \\
\hline BMI $\left(\mathrm{kg} / \mathrm{m}^{2}\right)$, mean $\pm \mathrm{SD}$ & $27.6 \pm 3.9$ & $27.9 \pm 5.3$ & $26.9 \pm 4.1$ & $27.5 \pm 4.1$ & 0.617 \\
\hline \multicolumn{6}{|l|}{ Outcome variables } \\
\hline $\mathrm{IC}, \mathrm{n}(\%)$ & $9(8.7)$ & I (4.3) & $32(91.4)$ & $42(25.9)$ & $<0.00 \mathrm{I}^{\mathrm{b}, \mathrm{a}}$ \\
\hline $\mathrm{ABI}(\mathrm{mmHg})$, mean $\pm \mathrm{SD}$ & $1.11 \pm 0.06$ & $0.94 \pm 0.02$ & $0.83 \pm 0.07$ & $1.03 \pm 0.13$ & $<\left.0.00\right|^{a, b, c}$ \\
\hline 6MWD (meters), mean \pm SD & $349.3 \pm 71.6$ & $298.1 \pm 77.3$ & $330.0 \pm 75.6$ & $338.0 \pm 75.0$ & $0.009^{c}$ \\
\hline $6 M W D$ (percent of predicted), mean \pm SD & $76.0 \pm 14.5$ & $67.6 \pm 14.4$ & $76.1 \pm 16.3$ & $74.8 \pm 15.1$ & $0.046^{c}$ \\
\hline IPAQ (score), mean \pm SD & $660.2 \pm 448.3$ & $880.4 \pm 716.3$ & $670.0 \pm 551.7$ & $693.6 \pm 518.4$ & 0.175 \\
\hline \multicolumn{6}{|l|}{ Eligibility criteria } \\
\hline CAD, n (\%) & $82(78.8)$ & $20(87.0)$ & $28(80.0)$ & $130(80.2)$ & 0.676 \\
\hline CVD, n (\%) & $15(14.4)$ & $6(26.1)$ & $5(14.3)$ & $26(16.0)$ & 0.367 \\
\hline Diabetes, n (\%) & $25(24.0)$ & $2(8.7)$ & $10(28.6)$ & $37(22.8)$ & 0.187 \\
\hline Metabolic syndrome, $\mathrm{n}(\%)$ & $73(70.2)$ & $14(60.9)$ & $28(80.0)$ & $115(7 I .1)$ & 0.279 \\
\hline Smoking, n (\%) & $20(19.2)$ & $3(13.0)$ & $5(14.3)$ & $28(17.3)$ & 0.675 \\
\hline HTN, n (\%) & $97(93.3)$ & $21(91.3)$ & $33(94.3)$ & $15 \mid(93.2)$ & 0.906 \\
\hline Age $>70$ years, $n(\%)$ & $19(18.3)$ & $9(39.1)$ & $16(45.7)$ & $44(27.2)$ & $0.003^{a, c}$ \\
\hline Dyslipidemia, n (\%) & $53(51.0)$ & $12(52.2)$ & $12(34.3)$ & $77(46.5)$ & 0.207 \\
\hline Asymptomatic carotid disease, $\mathrm{n}(\%)$ & $2(1.9)$ & I (4.3) & I (2.9) & $4(2.5)$ & 0.784 \\
\hline Family history of CAD, n (\%) & $40(38.5)$ & $3(13.0)$ & $13(37.1)$ & $56(34.6)$ & 0.064 \\
\hline CKD, n (\%) & $6(5.8)$ & $0(0.0)$ & $0(0.0)$ & $6(3.7)$ & 0.176 \\
\hline \multicolumn{6}{|l|}{ Medication use } \\
\hline Statin, n (\%) & $74(7 \mid .2)$ & $19(82.6)$ & $23(65.7)$ & $116(71.6)$ & 0.372 \\
\hline Acetylsalicylic acid, n (\%) & $62(59.6)$ & $18(78.3)$ & $23(65.7)$ & $103(63.6)$ & 0.233 \\
\hline Beta-blockers, n (\%) & $64(61.5)$ & $16(69.6)$ & $21(60.0)$ & $101(62.3)$ & 0.733 \\
\hline ACEI, n (\%) & $80(76.9)$ & $12(52.2)$ & $23(65.7)$ & $115(71.0)$ & $0.045^{c}$ \\
\hline ARB, $n(\%)$ & $7(6.7)$ & $3(13.0)$ & $3(8.6)$ & $13(8.0)$ & 0.596 \\
\hline Calcium channel blockers, n (\%) & $16(15.4)$ & $2(8.7)$ & $5(14.3)$ & $23(14.2)$ & 0.707 \\
\hline Oral anticoagulants, $\mathrm{n}(\%)$ & $30(28.8)$ & $6(26.1)$ & $7(20.0)$ & $43(26.5)$ & 0.590 \\
\hline
\end{tabular}

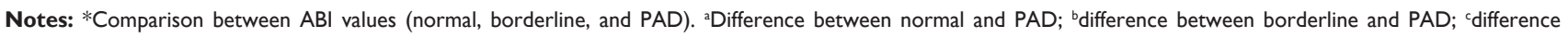
between normal and borderline.

Abbreviations: 6MWD, 6-minute walk distance; ABI, ankle-brachial index; ACEl, angiotensin-converting enzyme inhibitor; ARB, angiotensin II receptor blocker; BMI, body mass index; CAD, coronary artery disease; CKD, chronic kidney disease; CVD, cardiovascular diseases; HTN, hypertension; IC, intermittent claudication; IPAQ, International Physical Activity Questionnaire; PAD, peripheral artery disease.

was comprised of elderly patients, with approximately $43 \%$ and $33 \%$ of them having hypertension and diabetes, respectively. ${ }^{30}$ Another study conducted in France identified a PAD prevalence of $27.8 \%$ in a mixed population of patients $>55$ years old, with symptoms suggestive of PAD,

Table 2 Pearson's correlation coefficients $(r)$ and confidence intervals between outcome variables and absolute distance walked in the 6MWT

\begin{tabular}{llll}
\hline Variable & $\boldsymbol{r}$ & $\mathbf{9 5 \%} \mathbf{C I}$ & $\boldsymbol{P}$-value \\
\hline Age (years) & -0.347 & -0.47 to -0.17 & $<0.00 \mathrm{I}$ \\
IPAQ (score) & 0.164 & $0.23-0.30$ & 0.038 \\
$\mathrm{ABI}$ & 0.216 & $0.07-0.34$ & 0.006 \\
$\mathrm{IC}(0=$ yes, I= no) & 0.785 & $0.67-0.89$ & $<0.00 \mathrm{I}$ \\
\hline
\end{tabular}

Abbreviations: 6MWT, 6-minute walk test; $A B I$, ankle-brachial index; $\mathrm{Cl}$, confidence interval; IC, intermittent claudication; IPAQ, International Physical Activity Questionnaire. or established atherothrombotic disease, or two or more CVD risk factors. ${ }^{31}$

Our finding that patients with borderline PAD presented a lower 6MWD compared with individuals with normal $\mathrm{ABI}$ values is consistent with a prior study that showed that persons with borderline $\mathrm{ABI}$ values have higher rates of

Table 3 Multiple linear regression analysis with distance walked in 6MWT as the dependent variable

\begin{tabular}{llll}
\hline Variable & Coefficient B & $\mathbf{9 5 \%} \mathbf{C l}$ & P-value \\
\hline Constant & 419.214 & $221.3-6 \mid 7 . I$ & $<0.00 \mathrm{I}$ \\
Age (years) & -2.788 & -4.34 to -1.23 & $0.00 \mathrm{I}$ \\
$\mathrm{ABI}$ & $\mathrm{I} 3 \mathrm{I} .386$ & $26.2-236.49$ & $0.00 \mathrm{I}$ \\
$\mathrm{IC}(0=$ yes, I= no) & 34.737 & $3.50-65.96$ & 0.029 \\
\hline
\end{tabular}

Note: $R_{\text {adiusted }}^{2}=0.147$.

Abbreviations: 6MWT, 6-minute walk test; $\mathrm{ABI}$, ankle-brachial index; $\mathrm{Cl}$, confidence interval; IC, intermittent claudication. 
functional decline at 5-years' follow-up. ${ }^{32}$ Another study showed that even patients with borderline ABI values have a higher prevalence of subclinical atherosclerosis in the coronary and cerebrovascular arterial beds than patients with a normal ABI. ${ }^{33}$

Most patients with borderline PAD in our study were asymptomatic; this has been previously reported in older community-dwelling men and women. ${ }^{34}$ However, previous research has shown a higher prevalence of IC in patients with borderline $\mathrm{ABI}$ values than in those with normal $\mathrm{ABI}{ }^{35}$ In the present study, among patients with claudication, the ABI was abnormal in $91.4 \%$. Thus, the ABI value was shown in the present study to be valuable for detecting abnormalities in both symptomatic and asymptomatic individuals with or at a high risk of CVD.

As expected, a strong positive correlation was found between 6MWD and absence of IC. These results corroborate findings of a previous study showing that, in comparison with individuals without PAD, the presence and severity of PAD and developing IC are associated with significant functional decline, assessed by the 6MWD over a 2-year follow-up period. ${ }^{36}$ Regarding the weak positive correlation between functional capacity and ABI, studies have shown that as a consequence of the ischemic process, patients with abnormal ABI values show adaptations of the contractile tissues of the muscle with resulting deterioration of the muscle fibers. ${ }^{37}$ These alterations reduce muscle strength and, thus, may worsen functional capacity. ${ }^{38}$ In parallel, Safar et $\mathrm{al}^{39}$ demonstrated that there is a strong positive correlation between reduced walked distance and vascular bed reserve in patients with PAD.

In our study, the 6MWD showed moderate negative correlation with age. Similar results have been reported in the literature. In a study conducted in patients with type 2 diabetes mellitus, Adeniyi et $\mathrm{al}^{40}$ found a moderate negative correlation between the same variables evaluated in the present study. Furthermore, interest is growing in the early diagnosis of PAD, not only due to its increased prevalence associated with an aging population, but also because it is related to atherosclerotic disease in other regions of the vasculature, such as coronary and cerebral. ${ }^{41}$

Regarding the weak positive correlation of 6MWD with the IPAQ score, this result is consistent with findings from a previous study ${ }^{42}$ that showed weak correlations between the same variables in patients with chronic obstructive pulmonary disease. In contrast to previous studies, ${ }^{43,44}$ our study showed that all patients were classified as sufficiently active according to IPAQ. This interesting finding probably reflects the fact that our sample came from a reference cardiology outpatient clinic, where patients are strongly encouraged to practice unsupervised physical activity. It has been suggested that in patients with PAD, physical activity has proven effects on some of the abnormalities, which take part in the different steps of the constitution of the atheromatous lesion and of its possible thrombosis evolution. ${ }^{45}$

The multiple linear regression model revealed that age, $\mathrm{ABI}$, and absence of IC were independent predictors that altered the 6MWD. These findings support the use of the $6 \mathrm{MWT}$, a simple office-based test of functional capacity, as a diagnostic routine test in the population at risk of development of PAD, for the early detection of impaired functional capacity. The 6MWD may provide additional predictive information about PAD beyond traditional risk factors and scores in patients seen in a cardiology outpatient clinic, and it also predicts cardiovascular events in patients with stable coronary heart disease. ${ }^{46}$ Furthermore, ABI is the screening test of choice for the early detection of PAD in patients considered at high risk, due its simplicity, reproducibility, and cost effectiveness. ${ }^{47}$ Even so, this critical test is underutilized. ${ }^{47}$ The transition from asymptomatic borderline PAD to established PAD with claudication can also be quite rapid unless preventive measures are used. The clinical implications of this study are for the secondary prevention of CVD and are in agreement with the current trend in identifying high-risk patients for future cardiovascular and cerebrovascular mortality.

\section{Study limitations}

There are several limitations that need to be acknowledged and addressed regarding the present study. First, the sample was recruited at a single reference care center for cardiology in Southern Brazil. The second limitation was the advanced age of the sample; greater vascular impairment should be considered in this age group, since the patients who had claudication also had altered ABI. Third, measurements of the ABI after 6MWT, which enhances the sensitivity of PAD detection, and the distance walked at the onset of claudication pain, also known as the initial claudication distance, were not performed. These issues should be considered in future studies, since they could have interfered with the results.

\section{Conclusion}

Our study demonstrates that 6MWD is associated with the IPAQ score, ABI, and absence of IC. Age, ABI, and absence of IC were independently associated with functional 
capacity in patients with or at high risk of CVD recruited from a reference cardiology outpatient clinic in Southern Brazil. These findings support the use of the 6MWT as a diagnostic routine test in the population at risk of developing PAD, for the early detection of impaired functional capacity. The 6MWD may provide additional predictive information about PAD beyond traditional risk factors and scores in patients seen in a cardiology outpatient clinic. We also recommend screening for low ABI in the secondary care setting, at least in patients presenting cardiovascular risk factors.

\section{Disclosure}

The authors report no conflicts of interest in this work.

\section{References}

1. World Health Organization (WHO). The World Health Report 2005: Health Systems: Improving Performance. Geneva: WHO; 2005.

2. Gaziano T, Reddy KS, Paccaud F, et al. Cardiovascular disease. In: Jamison DT, Breman JG, Measham AR, et al, editors. Disease Control Priorities in Developing Countries. 2nd ed. Washington (DC): World Bank; 2006;645-662.

3. Newman AB, Siscovick DS, Manolio TA, et al. Ankle-arm index as a marker of atherosclerosis in the cardiovascular health study. Cardiovascular Heart Study (CHS) Collaborative Research Group. Circulation. 1993;88(3):837-845.

4. Makdisse M, Pereira Ada C, Brasil Dde P, et al. Prevalence and risk factors associated with peripheral arterial disease in the Hearts of Brazil Project. Arq Bras Cardiol. 2008;91(6):370-382.

5. Norgren L, Hiatt WR, Dormandy JA, et al. Inter-Society Consensus for the Management of Peripheral Arterial Disease (TASC II). Eur J Vasc Endovasc Surg. 2007;33 Suppl 1:S1-S75.

6. Hirsch AT, Criqui MH, Treat-Jacobson D, et al. Peripheral arterial disease detection, awareness, and treatment in primary care. JAMA. 2001;286(11):1317-1324.

7. McDermott MM, Greenland P, Liu K, et al. Leg symptoms in peripheral arterial disease. associated clinical characteristics and functional impairment. JAMA. 2001;286(13):1599-1606.

8. Arena R, Myers J, Williams MA, et al. Assessment of functional capacity in clinical and research settings: a scientific statement from the American Heart Association Committee on Exercise, Rehabilitation, and Prevention of the Council on Clinical Cardiology and the Council on Cardiovascular Nursing. Circulation. 2007;116(3):329-343.

9. Guyatt GH, Sullivan MJ, Thompson PJ, et al. The 6-minute walk: a new measure of exercise capacity in patients with chronic heart failure. Can Med Assoc J. 1985;132(8):919-923.

10. ATS Committee on Proficiency Standards for Clinical Pulmonary Function Laboratories. ATS statement: guidelines for the six-minute walk test. Am J Respir Crit Care Med. 2002;166(1):111-117.

11. Szuba A, Oka RK, Harada R, Cooke JP. Limb hemodynamics are not predictive of functional capacity in patients with PAD. Vasc Med. 2006;11(3):155-163.

12. Paul P, Naylor CD, Armstrong PW, Mark DB, Theroux P, Dagenais GR. Assessment of activity status and survival according to the Canadian Cardiovascular Society angina classification. Can J Cardiol. 2009; 25(7):e225-231.

13. Aho K, Harmsen P, Hatano S, Marquardsen J, Smirnov VE, Strasser T. Cerebrovascular disease in the community: results of a WHO collaborative study. Bull World Health Organ. 1980;58(1):113-130.

14. American Diabetes Association. Diagnosis and classification of diabetes mellitus. Diabetes Care. 2006;29 Suppl 1:S43-S48.
15. National Cholesterol Education Program (NCEP) Expert Panel on Detection, Evaluation, and Treatment of High Blood Cholesterol in Adults (Adult Treatment Panel III). Third report of the National Cholesterol Education Program (NCEP) Expert Panel on Detection, Evaluation, and Treatment of High Blood Cholesterol in Adults (Adult Treatment Panel III) final report. Circulation. 2002;106(25):3143-3421.

16. Reichert J, Araújo AJ, Gonçalves CM, et al. Smoking cessation guidelines - 2008. J Bras Pneumol. 2008;34(10):845-880. English, Portuguese.

17. IV Brazilian Guidelines in Arterial Hypertension Work Groups. [IV Brazilian Guidelines in Arterial Hypertension]. Arq Bras Cardiol. 2004;82 Suppl 4:7-22. English, Portuguese.

18. Expert Panel on Detection, Evaluation, and Treatment of High Blood Cholesterol in Adults. Executive summary of the Third Report of the National Cholesterol Education Program (NCEP) Expert Panel on Detection, Evaluation, and Treatment of High Blood Cholesterol in Adults (Adult Treatment Panel III). JAMA. 2001;285(19): 2486-2497.

19. Goessens BM, Visseren FL, Kappelle LJ, Algra A, van der Graaf Y. Asymptomatic carotid artery stenosis and the risk of new vascular events in patients with manifest arterial disease: the SMART study. Stroke. 2007;38(5):1470-1475.

20. da Cunha-Filho IT, Pereira DAG, de Carvalho AMB, Garcia JP, Mortimer LM, Burni IC. Correlation between ankle-brachial index before and after shuttle walk test. Jornal Vascular Brasileiro. 2007;6(4):332-338.

21. Syvänen K, Korhonen P, Partanen A, Aarnio P. Endothelial function in a cardiovascular risk population with borderline ankle-brachial index. Vasc Health Risk Manag. 2011;23(7):97-101.

22. Rooke TW, Hirsch AT, Misra S, et al. 2011 ACCF/AHA Focused Update of the Guideline for the Management of Patients With Peripheral Artery Disease (updating the 2005 guideline): a report of the American College of Cardiology Foundation/American Heart Association Task Force on Practice Guidelines. J Am Coll Cardiol. 2011;58(19):2020-2045.

23. Matsudo S, Araújo T, Matsudo V, et al. Questionário Internacional de Atividade Física (IPAQ): estudo de validade e reprodutibilidade no Brasil. Rev Bras Ativ Fís Saúde. 2001;6(2):5-18. Portuguese.

24. dos Santos Fde M, Borges MC, Correia MI, Telles RW, Lanna CC. Assessment of nutritional status and physical activity in systemic lupus erythematosus patients. Rev Bras Reumatol. 2010;50(6):631-638.

25. Matsudo S, Matsudo V, Araújo T, et al. Nível de atividade física na população do Estado de São Paulo: análise de acordo com o gênero, idade e nível socioeconômico, distribuição geográfica e de conhecimento. Rev Bras Ciênc Mov 2002;10(4):41-50. Portuguese.

26. Troosters T, Gosselink R, Decramer M. Six minute walking distance in healthy elderly subjects. Eur Respir J. 1999;14(2):270-274.

27. Borg G. Borg's Perceived Exertion and Pain Scales. Champaign, IL: Human Kinetics, 1998.

28. Makdisse M, Nascimento Neto R, Chagas AC, et al. Cross-cultural adaptation and validation of the Brazilian Portuguese version of the Edinburgh Claudication Questionnaire. Arq. Bras Cardiol. 2007;88(5):501-506. English, Portuguese.

29. Ankle Brachial Index Collaboration, Fowkes FG, Murray GD, et al. Ankle brachial index combined with Framingham Risk Score to predict cardiovascular events and mortality: a meta-analysis. JAMA. 2008;300(2):197-208.

30. Garofolo L, Ferreira SR, Miranda Junior F. Study of risk factors associated with peripheral arteriopathy in Japanese-Brazilians from Bauru (SP). Arq Bras Cardiol. 2014;102(2):143-150.

31. Cacoub P, Cambou JP, Kownator S, et al. Prevalence of peripheral arterial disease in high-risk patients using ankle-brachial index in general practice: a cross-sectional study. Int J Clin Pract. 2009;63(1): 63-70.

32. McDermott MM, Guralnik JM, Tian L, et al. Associations of borderline and low normal ankle-brachial index values with functional decline at 5-year follow-up: the WALCS (Walking and Leg Circulation Study). J Am Coll Cardiol. 2009;53(12):1056-1062. 
33. McDermott MM, Liu K, Criqui MH, et al. Ankle-brachial index and subclinical cardiac and carotid disease: the multi-ethnic study of atherosclerosis. Am J Epidemiol. 2005;162(1):33-41.

34. McDermott MM, Applegate WB, Bonds DE, et al. Ankle brachial index values, leg symptoms, and functional performance among communitydwelling older men and women in the lifestyle interventions and independence for elders study. J Am Heart Assoc. 2013;2(6):e000257.

35. Wang JC, Criqui MH, Denenberg JO, McDermott MM, Golomb BA, Fronek A. Exertional leg pain in patients with and without peripheral arterial disease. Circulation. 2005;112(22):3501-3508.

36. McDermott MM, Liu K, Greenland P, et al. Functional decline in peripheral arterial disease: associations with the ankle brachial index and leg symptoms. JAMA. 2004;292(4):453-461.

37. McGuigan MR, Bronks R, Newton RU, et al. Muscle fiber characteristics in patients with peripheral arterial disease. Med Sci Sports Exerc. 2001;33(12):2016-2021.

38. Pereira DAG, Faria BMA, Gonçalves RAM, et al. Relação entre força muscular e capacidade funcional em pacientes com doença arterial obstrutiva periférica: um estudo piloto. Jornal Vascular Brasileiro. 2011;10(1):26-30. Portuguese.

39. Safar ME, Totomoukouo JJ, Asmar RA, Laurent SM. Increased pulse pressure in patients with arteriosclerosis obliterans of the lower limbs. Arteriosclerosis. 1987;7(3):232-237.

40. Adeniyi AF, Uloko AE, Sani-Suleiman I. Relationship between the 6-minute walk test and correlates of Type 2 Diabetes: indication for caution in exercise prescription. AJPARS. 2010;2(1):21-24.
41. Criqui MH, Langer RD, Fronek A, et al. Mortality over a period of 10 years in patients with peripheral arterial disease. $N$ Engl J Med. 1992;326(6):381-386.

42. Nyssen SM, Santos JG, Barusso MS, Oliveira Jr AD, Lorenzo VA, Jamami M. Levels of physical activity and predictors of mortality in COPD. J Bras Pneumol. 2013;39(6):659-666. English, Portuguese.

43. Stein RA, Rockman CB, Guo Y, et al. Association Between Physical Activity and Peripheral Artery Disease and Carotid Artery Stenosis in a Self-Referred Population of 3 Million Adults. Arterioscler Thromb Vasc Biol. Epub October 30, 2014.

44. Barbosa JP, Henriques PM, de Barros MV, Wolosker N, Medes RittaDias R. Physical activity level in individuals with peripheral arterial disease: a systematic review. Jornal Vascular Brasileiro. 2012;11(1): 22-28.

45. Cassar K, Bachoo P, Ford I, Greaves M, Brittenden J. Markers of coagulation activation, endothelial stimulation and inflammation in patients with peripheral arterial disease. Eur J Vasc Endovasc Surg. 2005;29(2):171-176.

46. Beatty AL, Schiller NB, Whooley MA. Six-minute walk test as a prognostic tool in stable coronary heart disease: data from the heart and soul study. Arch Intern Med. 2012;172(14):1096-1102.

47. Khan TH, Farooqui FA, Niazi K. Critical review of the ankle brachial index. Curr Cardiol Rev. 2008;4(2):101-106.
International Journal of General Medicine

\section{Publish your work in this journal}

The International Journal of General Medicine is an international, peer-reviewed open-access journal that focuses on general and internal medicine, pathogenesis, epidemiology, diagnosis, monitoring and treatment protocols. The journal is characterized by the rapid reporting of reviews, original research and clinical studies across all disease areas.

\section{Dovepress}

A key focus is the elucidation of disease processes and management protocols resulting in improved outcomes for the patient.The manuscript management system is completely online and includes a very quick and fair peer-review system. Visit http://www.dovepress.com/ testimonials.php to read real quotes from published authors. 